\title{
Numerical simulation and optimization of aerodynamic uplift force of a high-speed pantograph
}

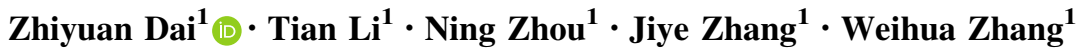

Received: 29 April 2021 /Revised: 21 August 2021/Accepted: 23 August 2021 / Published online: 6 October 2021

(C) The Author(s) 2021

\begin{abstract}
Aiming at the problem that aerodynamic uplift forces of the pantograph running in the knuckle-downstream and knuckle-upstream conditions are inconsistent, and their magnitudes do not satisfy the corresponding standard, the aerodynamic uplift forces of pantographs with baffles are numerically investigated, and an optimization method to determine the baffle angle is proposed. First, the error between the aerodynamic resistances of the pantograph obtained by numerical simulation and wind tunnel test is less than $5 \%$, which indicates the accuracy of the numerical simulation method. Second, the original pantograph and pantographs equipped with three different baffles are numerically simulated to obtain the aerodynamic forces and moments of the pantograph components. Three different angles for the baffles are $-17^{\circ}, 0^{\circ}$ and $17^{\circ}$. Then the multibody simulation is used to calculate the aerodynamic uplift force of the pantograph, and the optimal range for the baffle angle is determined. Results show that the lift force of the baffle increases with the increment of the angle in the knuckle-downstream condition, whereas the lift force of the baffle decreases with the increment of the angle in the knuckle-upstream condition. According to the results of the aerodynamic uplift force, the optimal angle of the baffle is determined to be $4.75^{\circ}$ when the running speed is $350 \mathrm{~km} / \mathrm{h}$, and pantograph-catenary contact forces are $128.89 \mathrm{~N}$ and $129.15 \mathrm{~N}$ under the knuckledownstream and knuckle-upstream operating conditions,
\end{abstract}

Tian Li

litian2008@home.swjtu.edu.cn

Zhiyuan Dai

daizhiyuan18@my.swjtu.edu.cn

1 State Key Laboratory of Traction Power, Southwest Jiaotong University, Chengdu 610031, China respectively, which are almost equal and both meet the requirements of the standard EN50367:2012.

Keywords High-speed pantograph · Aerodynamic uplift force $\cdot$ Baffle $\cdot$ Numerical simulation $\cdot$ Multibody simulation

\section{Introduction}

The static and aerodynamic uplift forces are important components of the pantograph-catenary contact force of a high-speed train, in addition to dynamic components caused by vibration $[1,2]$. The static uplift force is provided by the airbag, and the aerodynamic uplift force is the force between the strip and the catenary under the action of aerodynamic forces and moments of the pantograph components. The pantograph-catenary contact force is an important factor that affects the quality of current collection. If the contact force is too large, it will increase the wear of the strip and the contact wire. When the contact force is too small, it will increase the resistance of current collection, and also produce arc [3]. Moreover, the connection between the pantograph and the catenary will be broken when the contact force is zero, and arc discharge will occur, which will cause ablation of the catenary line and strip, and seriously affect the running safety of trains $[4,5]$.

The effect of aerodynamics performance on the pantograph-catenary system was ignored when the train was running at a low speed [6, 7]. However, the aerodynamic effect cannot be ignored with the increment of the 
operating speed. When the running speed is not less than $250 \mathrm{~km} / \mathrm{h}$, the aerodynamic resistance accounts for about $75 \%-80 \%$ of the total resistance [8-10], and the aerodynamic resistance of the pantograph accounts for about $12 \%$ of the total aerodynamic resistance [11]. Moreover, aerodynamic forces have a significant effect on the contact force $[1,12]$. Therefore, it is necessary to study the effect of aerodynamics on the pantograph-catenary contact force. Song et al. [13] obtained the aerodynamic uplift force of the pantograph at a running speed of $350 \mathrm{~km} / \mathrm{h}$ using an empirical formula by means of computational fluid dynamics. Yang et al. [14, 15] obtained the aerodynamic uplift forces of pantographs under the conditions of considering the drag and lift forces of the pantograph rods and panhead. However, the effect of the moment of pantograph components on the aerodynamic uplift force was ignored. Li et al. [16] proposed a new method to calculate the aerodynamic uplift force of a pantograph based on the statics analysis method. The variation of the uplift force was consistent with the results of the wind tunnel test. However, the pantograph was simplified to a two-dimensional model, and the effect of moment was also ignored. Based on the multibody simulation, a comprehensive dynamic model with aerodynamic forces and moments of each pantograph component is established, and a new method to calculate the aerodynamic uplift force of the pantograph is proposed in this study.

Meanwhile, the longitudinal asymmetry of the pantograph leads to differences in the aerodynamic uplift force under the knuckle-downstream and knuckle-upstream conditions. As a result, manual adjustment of the airbag or the control system can regulate the static uplift force when the high-speed train is running in different directions, so as to make the pantograph-catenary contact force meet the requirements. Therefore, the dependence on the airbag system can be reduced by adjusting the aerodynamic uplift forces under the knuckle-downstream and knuckle-upstream conditions to be close. It is of great significance to alleviate the fatigue damage of the airbag system and the possibility of pantograph-catenary accidents. In this study, the aerodynamic uplift force is optimized by means of setting the baffle. The calculation method and the optimization process of the aerodynamic uplift force of the pantograph proposed in this study are general, which can be applied to various types of pantographs, and can provide a reference for the design and optimization of high-speed pantographs.

\section{Computational model}

\subsection{Geometry and mathematical models}

A type of pantograph used in China is adopted to build the models. The height of the pantograph is $1600 \mathrm{~mm}$, and there are no baffles installed on the panhead for the original pantograph, as shown in Fig. 1a. The panhead in Fig. 1b is equipped with baffles, whose angle can be adjusted to optimize the aerodynamic uplift force of the pantograph.

The running speed of the high-speed train is lower than $360 \mathrm{~km} / \mathrm{h}$ in this study, and the fluid can be considered as the incompressible one [17]. Therefore, the incompressible Reynolds averaged Navier-Stokes (RANS) and $k-\omega$ shear stress transport (SST) turbulence model are used to solve the governing equations $[18,19]$.

The upper arm, lower arm, upper link and lower link of the pantograph constitute a frame system, which has only one degree of freedom (DOF) of raising angle $\alpha$ [20]. The panhead has 6 DOFs as it is supported on springs, of which only the vertical displacement, roll and pitch angles are considered since they affect the pantograph-catenary contact force.

\subsection{Computational domain and boundary conditions}

The computational domain shown in Fig. 2 is established. A cuboid named T-body is set on the bottom of the domain to simulate the high-speed train body, and the pantograph is placed on the top of the T-body. A curved roof surface of the T-body and geometric changes of the T-body near the pantograph have little effect on the flow field above the pantograph. On the contrary, it will increase the number of grids and reduce computational efficiency. Therefore, the simplified train roof is used in numerical simulation. The origin of the coordinates is located on the base of the pantograph, as well as the longitudinal median plane of the computational domain, as shown in Fig. 1a and Fig. 2. The length of the computational domain is $60 \mathrm{~m}$, the height and width are $10 \mathrm{~m}$ and $20 \mathrm{~m}$, respectively. The distances between the pantograph and the inlet and outlet boundaries of the domain are both $30 \mathrm{~m}$. The selected computational domain satisfies the standard EN 14,067-6:2010 [21]. The other sizes of the computational domain are shown in Fig. 2.

The running speed of the high-speed pantograph is $300-350 \mathrm{~km} / \mathrm{h}$ in operation; therefore, $350 \mathrm{~km} / \mathrm{h}$ is selected in numerical simulation. When the pantograph is running in the knuckle downstream, the front side of the domain is set as the velocity inlet boundary, and the velocity is $97.22 \mathrm{~m} / \mathrm{s}$. Meanwhile, a pressure-outlet condition is prescribed at the 
(a)

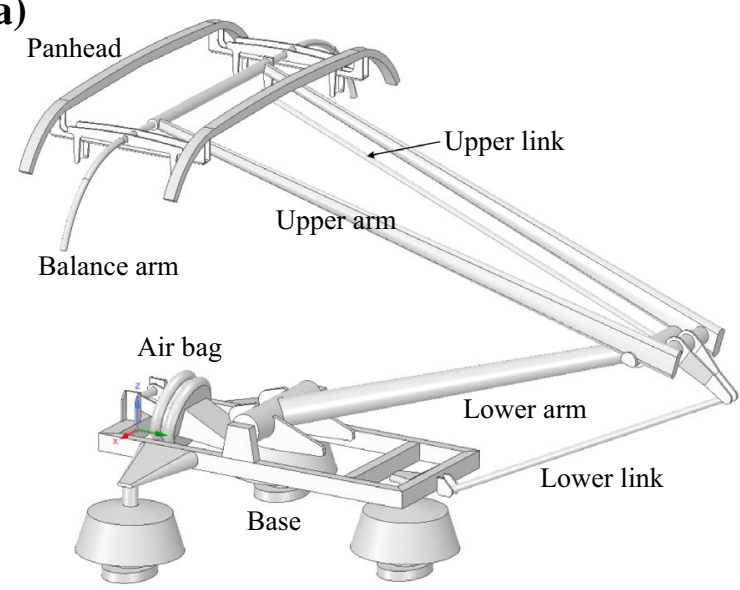

(b)

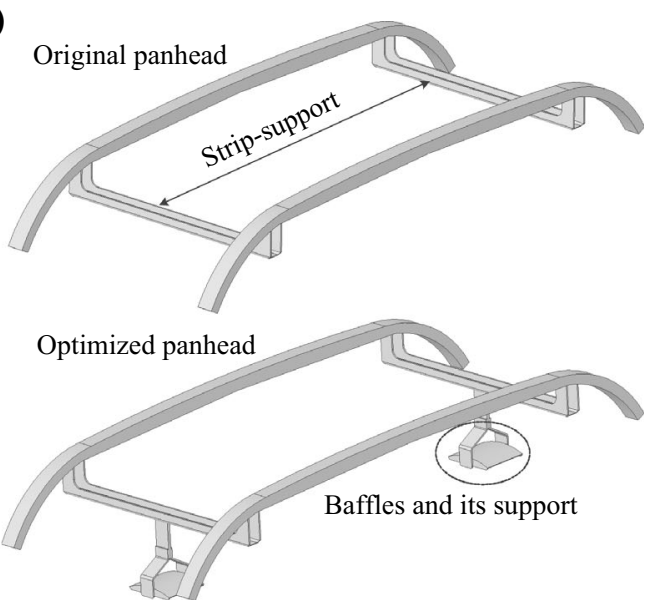

Fig. 1 Models of the pantograph and panheads: a pantograph and $\mathbf{b}$ panhead

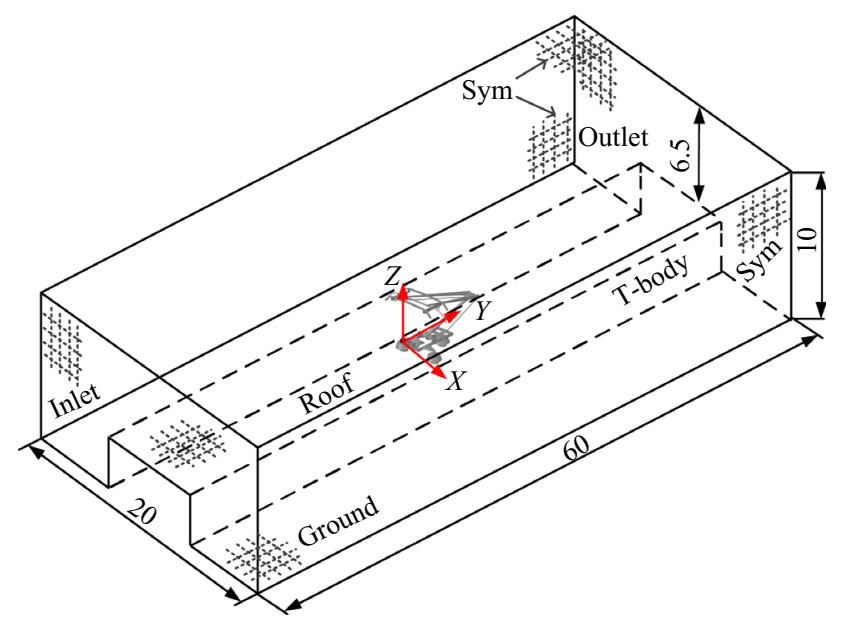

Fig. 2 Computational domain (unit: $\mathrm{m}$ )

back side of the domain with a magnitude of 0 . The setting of the knuckle-upstream condition is opposite to that of the knuckle-downstream condition. Symmetry condition is used to model zero-shear slip walls in viscous flows; therefore, the side and top boundaries are set as symmetry condition. The top and sides of the T-body are set as noslip wall, the ground is set as a slip wall, and the velocity is $97.22 \mathrm{~m} / \mathrm{s}$.

\section{Optimization process}

The flowchart for the numerical simulation and optimization of the aerodynamic uplift force of the pantograph can be described as follows.

Step 1 Carry out the mesh sensitivity firstly, and then the numerical simulation results are compared with the experimental data to verify the accuracy of the numerical simulation.

Step 2 Obtain the aerodynamic uplift forces of the pantograph running in both the knuckle-downstream and knuckle-upstream conditions, and judge whether the aerodynamic uplift forces are consistent in two conditions and whether the magnitudes satisfy the standard EN50367:2012 [22]. If one of them is not satisfied, the pantograph should be optimized.

Step 3 Obtain the aerodynamic uplift force of the pantograph with three different baffles. Three different angles for the baffles are $-17^{\circ}, 0^{\circ}$ and $17^{\circ}$. The limit is large enough to ensure that the optimal angle is included. Then, the optimal range of the baffle angle is determined according to the results of the aerodynamic uplift force. Step 4 Study the relationship between the aerodynamic lift force and the baffle angle by independently applying the aerodynamic study of the baffle, and determine the possible angle using the aerodynamic uplift forces of the pantograph with baffles. Establish the baffle models with different angles around the possible angle, and obtain the aerodynamic uplift forces of the pantograph. According to the results, judge whether the aerodynamic uplift forces are consistent in the knuckle-downstream and knuckle-upstream conditions, and whether the magnitudes satisfy the standard. If one of them is not satisfied, continuously find a suitable angle according to the previous results.

The above procedures are illustrated in Fig. 3. 


\section{Validation of numerical simulation}

\subsection{Mesh sensitivity}

Three regions are set in the computational domain to refine the mesh. The basic size of the mesh is $H$, and the sizes of the three zones are $\frac{H}{2^{3}}, \frac{H}{2^{2}}, \frac{H}{2}$, respectively. Meanwhile, the cell size of the pantograph surface is $\frac{H}{2^{7}}-\frac{H}{2^{4}}$. There are 18 boundary layers in total. The height of the first boundary layer is $0.01 \mathrm{~mm}$, and the growth ratio is 1.2 . The boundary layers ensure that the $y+$ of the pantograph is around 1 . The cells of the boundary layer and refined regions are shown in Fig. 4. In order to study the influence of the mesh quantity on the numerical results, 4 basic sizes of 130, 140, 150 and $160 \mathrm{~mm}$ are chosen to generate 4 different meshes, which are named mesh 1 , mesh 2, mesh 3 and mesh 4, respectively, and the number of cells are 20.53 million, 25.20 million, 31.20 million and 36.6 million, respectively.

Four meshes are numerically simulated to obtain the aerodynamic forces of the strip, panhead and pantograph, as shown in Table 1. Figure 5 shows the pressure distribution along a line, which is $650-4000 \mathrm{~mm}$ behind the strip at a height of $z=1260 \mathrm{~mm}$, and it is located on the section of $x=0$.

It can be seen from the aerodynamic forces that the results obtained using mesh 3 and mesh 4 are close, the differences in lift forces of the strip and panhead are both less than $1 \mathrm{~N}$, and all the relative errors of resistance between mesh 3 and mesh 4 are less than 1\%. As shown in Fig. 5, the pressure distribution for 4 meshes is basically the same from 1500 to $4000 \mathrm{~mm}$. The pressure distribution obtained using mesh 3 and mesh 4 at a position closer to the strip is also basically the same, and the results of aerodynamic forces and pressure distribution in the flow field show that the accuracy of mesh 3 and mesh 4 is equivalent, mesh 3 will be used for numerical simulation in subsequent work considering the calculation efficiency.

\subsection{Experimental validation}

A pantograph is meshed with the same size as Mesh 3, which was tested in a wind tunnel at the China Aerodynamics Research and Development Center [23]. The speed range of the wind tunnel test is $300-500 \mathrm{~km} / \mathrm{h}$, and the aerodynamic drag coefficient $C_{\mathrm{d}}$ of the pantograph in this speed range is obtained. The aerodynamic drag coefficient $C_{\mathrm{d}}$ is defined as.

$C_{\mathrm{d}}=\frac{F_{\mathrm{d}}}{0.5 \rho v^{2} S}$,

where $F_{\mathrm{d}}$ is the aerodynamic drag force, $\rho$ is the density of the airflow, $v$ is the speed of the incoming flow, and $S$ is the windward area. In this paper, $S$ is assumed to be 1 as the experimental pantograph of each condition is the same.

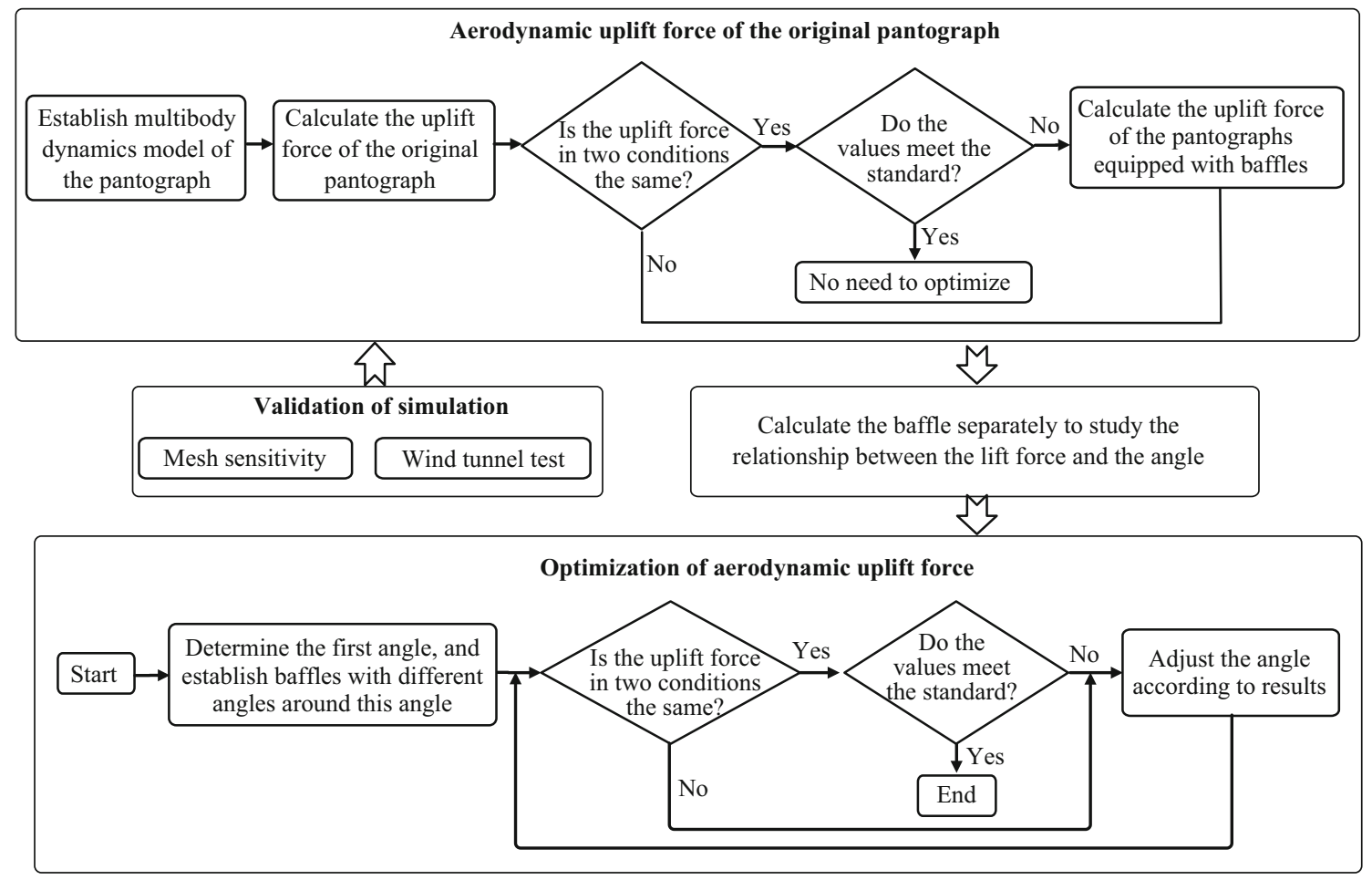

Fig. 3 Optimization process 


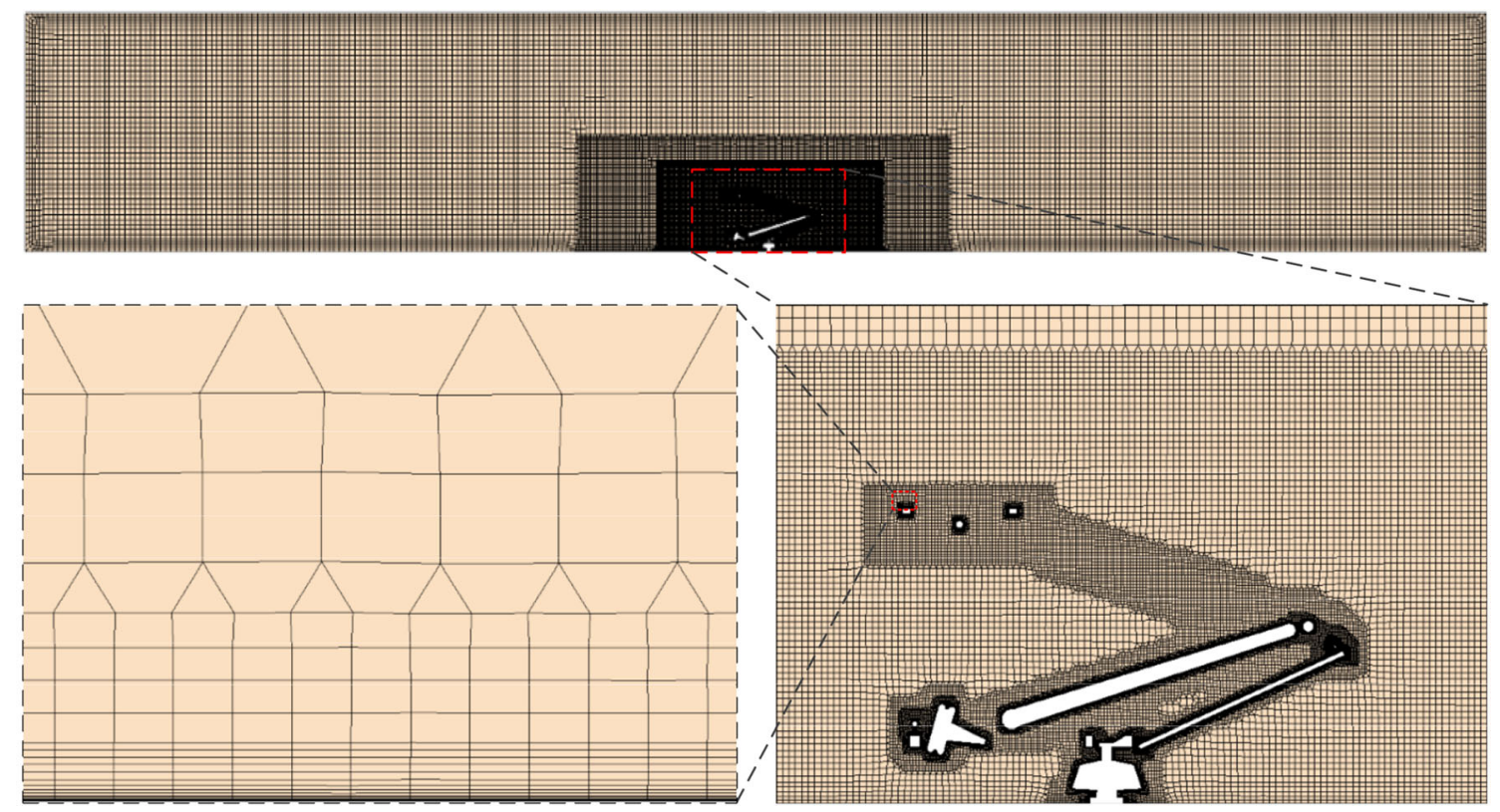

Fig. 4 Computational meshes

Table 1 Aerodynamic force of the pantograph and its components (N)

\begin{tabular}{llllll}
\hline Mesh & Lift force of strip & Lift force of panhead & Drag force of strip & Drag force of panhead & Drag force of pantograph \\
\hline 1 & -15.75 & -10.06 & 576.10 & 721.79 & 2175.00 \\
2 & -16.47 & -10.25 & 585.07 & 731.18 & 2290.49 \\
3 & -17.59 & -10.82 & 594.51 & 744.12 & 2196.41 \\
4 & -17.76 & -11.02 & 596.92 & 746.63 & 2200.05 \\
\hline
\end{tabular}

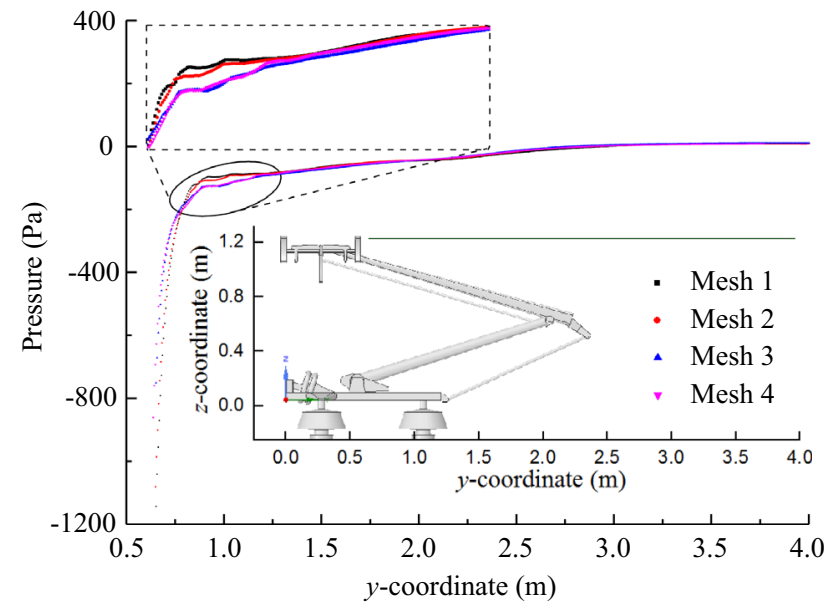

Fig. 5 Pressure distribution in the flow field

Numerical simulation is performed on the experimental pantograph, and the running speed of the pantograph is $97.22 \mathrm{~m} / \mathrm{s}$, which is $350 \mathrm{~km} / \mathrm{h}$. The aerodynamic drag coefficients of the experimental pantograph obtained using numerical simulation are compared with the experimental results in order to verify the accuracy of the numerical simulation, as listed in Table 2.

It can be seen from Table 2 that the aerodynamic drag coefficient of the pantograph obtained from numerical simulation is slightly less than that of the wind tunnel test in both knuckle-downstream and upstream condition; however, the errors are within 5\%. Some small parts of the pantograph, such as bolts, nuts and wires, were deleted when meshing to improve the quality of the mesh. Therefore, the results of numerical simulation are slightly smaller. In summary, the numerical simulation in this study can accurately match the experimental results. The purpose of validations is to verify the reliability and accuracy of the numerical simulation method. Although there is no experimental data for aerodynamic lift force coefficient, the coincidence of aerodynamic resistance coefficient can also demonstrate that the numerical simulation method can reproduce the wind tunnel test well, so as to prove the accuracy of the numerical simulation method. 
Table 2 Aerodynamic drag coefficient obtained using the numerical simulation and wind tunnel test

\begin{tabular}{llll}
\hline Condition & Wind tunnel test & Numerical simulation & Relative error \\
\hline Knuckle downstream & 0.403 & 0.387 & $4.0 \%$ \\
Knuckle upstream & 0.390 & 0.372 & $4.6 \%$ \\
\hline
\end{tabular}

\section{Results}

\subsection{Calculation method of aerodynamic uplift force}

The 3D multibody simulation model of the pantograph is established using the software of SIMPACK, as shown in Fig. 6, and the system has only one DOF in the vertical direction. The aerodynamic drag and lift forces, aerodynamic moments in three directions are applied to each components of the pantograph. The strip is fixed on the catenary, and the reaction force of the contact point in the $z$ direction is solved, which is the aerodynamic uplift force of the pantograph. Upper arm, lower arm, balance arm, upper link, lower link and base are hinged to each other. Panhead and balance arm are connected by a spring, which is located between the balance arm and the strip-support, and the stiffness in $x, y$ and $z$ directions are all $10^{5} \mathrm{~N} / \mathrm{m}$.

Numerical simulations of multibody and fluid dynamics are performed on the original pantograph and the pantograph equipped with three different baffles. Three different angles for the baffles are $-17^{\circ}, 0^{\circ}$ and $17^{\circ}$, as shown in Fig. 7. The baffle angle of the pantograph currently in operation is mostly in the range of $10^{\circ}-15^{\circ}$. Based on the actual experience, this study takes the limit angle as $17^{\circ}$, and the limit angle is large enough to ensure that the optimal angle is included.

The aerodynamic uplift force of the pantograph, the lift force of the upper and lower surfaces of baffles are

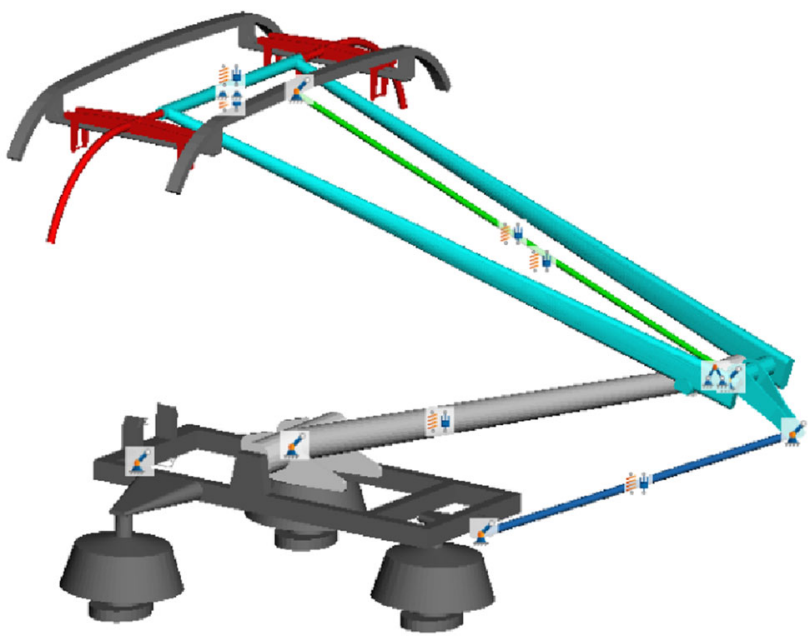

obtained, as shown in Table 3. It is noted that the upper and lower surfaces are the main parts that affect aerodynamic lift forces, so these two parts are analyzed separately. In addition to the upper and lower surfaces, the baffle also has other surfaces such as its support. According to the requirements in the standard EN50367:2012, the pantograph-catenary contact force should be in the range of $110-180 \mathrm{~N}$ when the operating speed is $350 \mathrm{~km} / \mathrm{h}$. The static uplift force provided by the airbag is $80 \mathrm{~N}$. It can be seen from Table 3 that the aerodynamic uplift forces of the original pantograph in the knuckle-downstream and knuckle-upstream conditions are -27.1 and $46.18 \mathrm{~N}$, respectively. The pantograph-catenary contact force satisfies the standard in the knuckle-downstream condition, while fails to satisfy the standard in the knuckle-upstream condition. In addition, the difference in the aerodynamic uplift forces of the original pantograph in two operating condition is relatively large, about $73 \mathrm{~N}$. Therefore, the original pantograph needs to be optimized.

The baffle is installed on the support of the strip, and its resistance and moments have no effect on the aerodynamic uplift force, and the aerodynamic lift force of the baffle will completely be transformed into the aerodynamic uplift force of the pantograph. As shown in Table 3, the change in the aerodynamic uplift force of the pantograph with baffles is almost the same as the aerodynamic lift force of the baffle, which indicate consistency of the results between the multibody and fluid dynamics. The $-17^{\circ}$ baffle provides a negative lift force in the knuckle-downstream condition, and a positive lift force in the knuckle-upstream condition, which intensifies the inconsistency of the aerodynamic uplift force of the original pantograph in two operating conditions. The $0^{\circ}$ baffle provide basically the same lift force in the knuckle-downstream and knuckleupstream conditions, about $36 \mathrm{~N}$. However, the inconsistency of aerodynamic uplift force is not improved. For the $17^{\circ}$ baffle, it can provide a larger positive aerodynamic lift force in the knuckle-downstream condition, and a negative lift one in the knuckle-upstream condition, which leads to a greater uplift force in the knuckle-downstream condition. Therefore, the optimal angle of the baffle should be in the range of $0^{\circ}-17^{\circ}$.

Fig. 6 Multibody simulation model of pantograph 


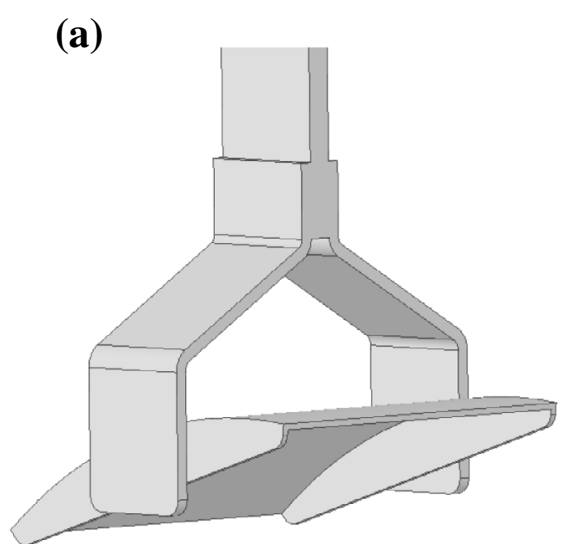

(b)

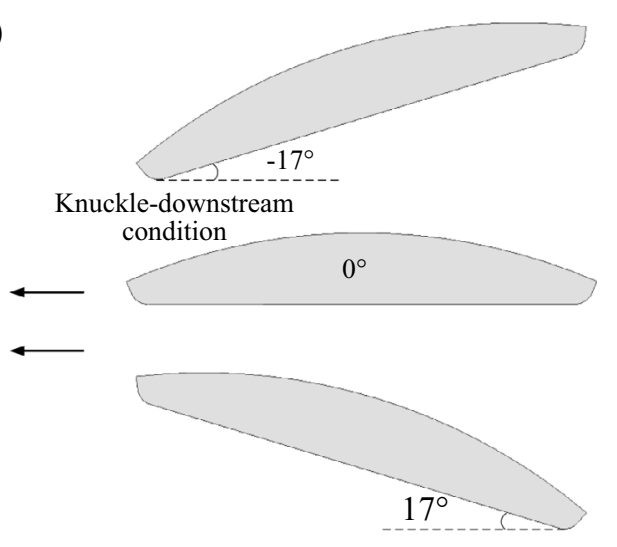

Fig. 7 The baffle model: a baffle and its support; $\mathbf{b}$ baffles with different angles

Table 3 Aerodynamic forces and uplift force of the pantograph

\begin{tabular}{|c|c|c|c|c|c|}
\hline Condition & Baffle angle $\left(^{\circ}\right)$ & $\begin{array}{l}\text { Lift force of the upper } \\
\text { surface of the baffle }(\mathrm{N})\end{array}$ & $\begin{array}{l}\text { Lift force of the lower } \\
\text { surface of the baffle }(\mathrm{N})\end{array}$ & $\begin{array}{l}\text { Lift force of the baffle } \\
\text { and its support }(\mathrm{N})\end{array}$ & $\begin{array}{l}\text { Aerodynamic } \\
\text { uplift force }(\mathrm{N})\end{array}$ \\
\hline \multirow[t]{4}{*}{ Knuckle downstream } & No baffle & - & - & - & -27.10 \\
\hline & -17 & 12.92 & -62.73 & -17.91 & -44.89 \\
\hline & 0 & 63.87 & -23.28 & 37.63 & 10.56 \\
\hline & 17 & 121.15 & 59.88 & 160.77 & 132.50 \\
\hline \multirow[t]{4}{*}{ Knuckle upstream } & No baffle & - & - & - & 46.18 \\
\hline & -17 & 122.29 & 57.57 & 157.62 & 202.47 \\
\hline & 0 & 59.31 & -26.08 & 36.16 & 81.47 \\
\hline & 17 & 15.41 & -64.65 & -20.74 & 26.15 \\
\hline
\end{tabular}

\subsection{Relationship between the aerodynamic lift force and baffle angle}

In order to improve the optimization efficiency, the relationship between the aerodynamic lift force and the baffle angle is studied by independently applying the aerodynamic study of the baffle. The baffle models with 9 angles of $0^{\circ}, 2^{\circ}, 4^{\circ}, 6^{\circ}, 8^{\circ}, 10^{\circ}, 12^{\circ}, 14^{\circ}$ and $17^{\circ}$ are selected, as shown in Fig. 8a.

The model of the baffle in the numerical simulation is shown in Fig. 7a, the overall height of the baffle is about $0.2 \mathrm{~m}$. Meanwhile, Fig. $8 \mathrm{~b}$ shows the computational domain for the isolated baffle, and the baffle is located at the center of the domain. The cell size of the baffle surface and the size of the surrounding cell are completely consistent with the main CFD model, as well as the boundary conditions and solving algorithm.

As shown in Fig. 8c, the lift force of the baffle increases with the angle in the knuckle-downstream condition, and it basically increases linearly. In the knuckle-upstream condition, the lift force of the baffle decreases as the angle increases. The decrease is almost linear when the angle is less than $12^{\circ}$, whereas the decreasing trend of the lift force slows down when the angle is greater than $12^{\circ}$.

Figure 9a shows the lift force of the upper and lower surfaces of the baffle in the knuckle-downstream condition. It can be seen that the lift forces of the upper and lower surfaces increase with the angle. The lift force of the upper surface increases slowly when the angle is small, whereas the lift force of the lower surface basically maintains the same increasing trend.

Figure 10 shows the pressure distribution around baffles with different angles in the knuckle-downstream condition. With the baffle angle increases, the negative pressure on the upper surface and the positive pressure on the lower surface both increase gradually; therefore, the lift forces of the upper and lower surfaces increase. There is a vortex underneath the baffle when the angle is less than $8^{\circ}$, and the lower surface of the baffle presents negative pressure. Therefore, the lower surface has a smaller lift force, and even shows a negative lift force when the angle is less than $4^{\circ}$. It can be seen from streamlines that the vortex gradually moves toward the front end of the baffle as the angle increases, the positive pressure at the rear end enlarges, and 

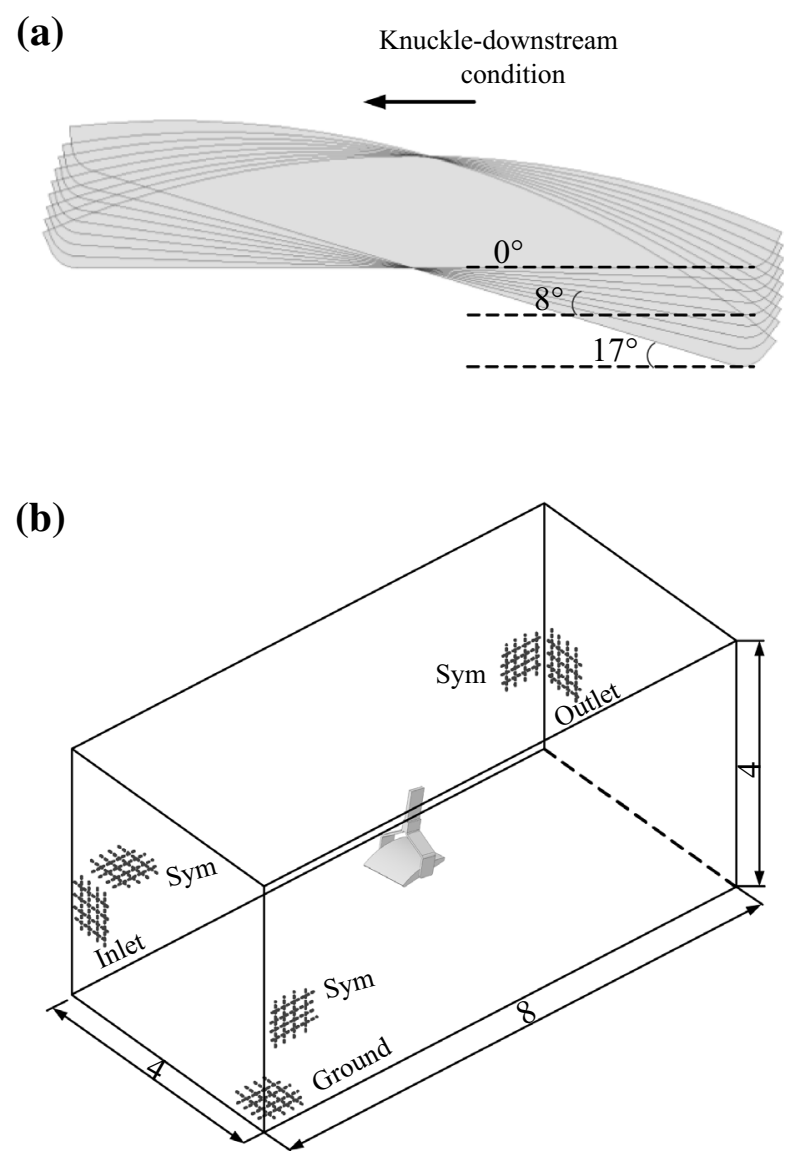

(c)

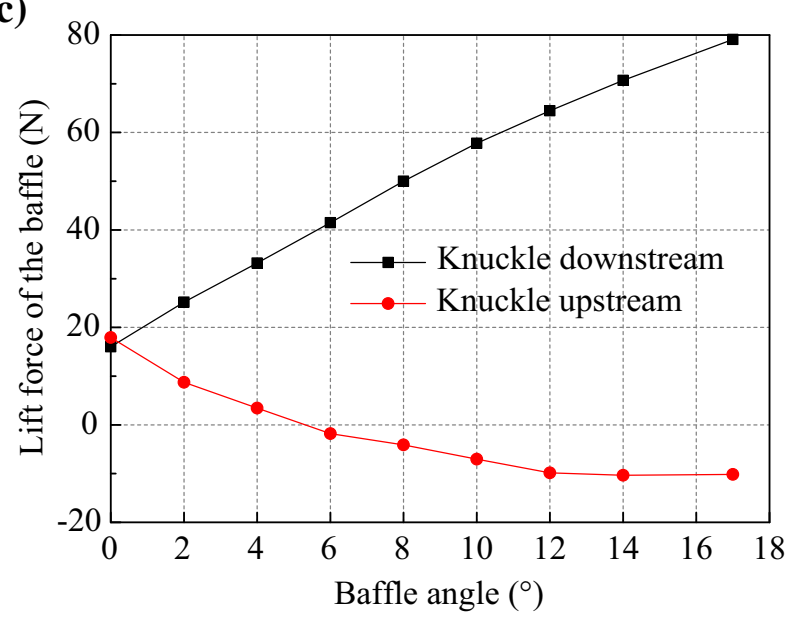

Fig. 8 Models and lift forces of baffles: a baffles with different angles; $\mathbf{b}$ computational domain for the baffle (unit: $\mathrm{m}$ ); $\mathbf{c}$ lift forces of baffles

the amplitude of the positive pressure also increases. Consequently, the lift of the lower surface improves. The increment of the baffle angle leads to an increase in the attack angle. Therefore, the air velocity above the upper surface of the baffle increases, and the negative pressure gradually enlarges, so as to the lift force of the upper surface increases.

As shown in Fig. 9a, the lift forces of the upper and lower surfaces of the baffle both decrease in the knuckleupstream condition. The lift forces of the upper surface decreases rapidly when the angle is less than $12^{\circ}$. When the angle is greater than $12^{\circ}$, the decrease of the lift force of the lower surface slows down, and then basically unchanged. Therefore, the trend of the lift force reduction slows down when the angle is greater than $12^{\circ}$ in the knuckleupstream condition. Figure 11 shows the pressure distribution around baffles with different angles in the knuckleupstream condition. When the angle is greater than $12^{\circ}$, the flow field around the baffle basically no longer changes, which is consistent with the lift force. For the upper surface of the baffle, the windward area becomes larger as the angle increases, and the positive pressure on the upper surface increase correspondingly. Therefore, the lift force of the upper surface keeps decreasing.

Table 4 shows the aerodynamic forces of baffles and uplift force of the pantograph, including the isolated baffle and that installed in the pantograph. Numerically simulating the baffle and its support separately, the lift forces of the baffle increase with the angle in the knuckle-downstream condition, whereas the lift forces of the baffle decrease in the knuckle-upstream condition. Moreover, the lift force of the baffle increases linearly with the angle in the knuckle-downstream condition. In the knuckle-upstream condition, the lift force of the baffle is also basically linear with the angle when the angle is less than $12^{\circ}$.

As shown in Table 4, when the pantograph with the baffle is numerically simulated, the lift forces of the baffle also increase with the angle in the knuckle-downstream condition. Meanwhile, the lift forces of the baffle decrease as the angle increase in the knuckle-upstream condition, which is consistent with the result of numerically simulating the baffles separately. Therefore, it exists that the lift forces of the baffle considering the pantograph or not is different. The difference is due to some disturbances to the flow field around the baffle when there are other components around the baffle. However, the relationship between the baffle lift force and the baffle angle can be used to deduce the variation of pantograph aerodynamic lift force with the existence of the baffle. The pantograph baffle can be optimized according to the conclusions above. It can be obtained that the aerodynamic uplift forces of the pantograph with the $5.8^{\circ}$ baffle in the knuckle-downstream and knuckle-upstream conditions are equal. Therefore, baffles with 5 different angles including $4^{\circ}, 5^{\circ}, 6^{\circ}, 7^{\circ}$ and $8^{\circ}$ are selected to be installed on the pantograph for the following numerical simulations. 

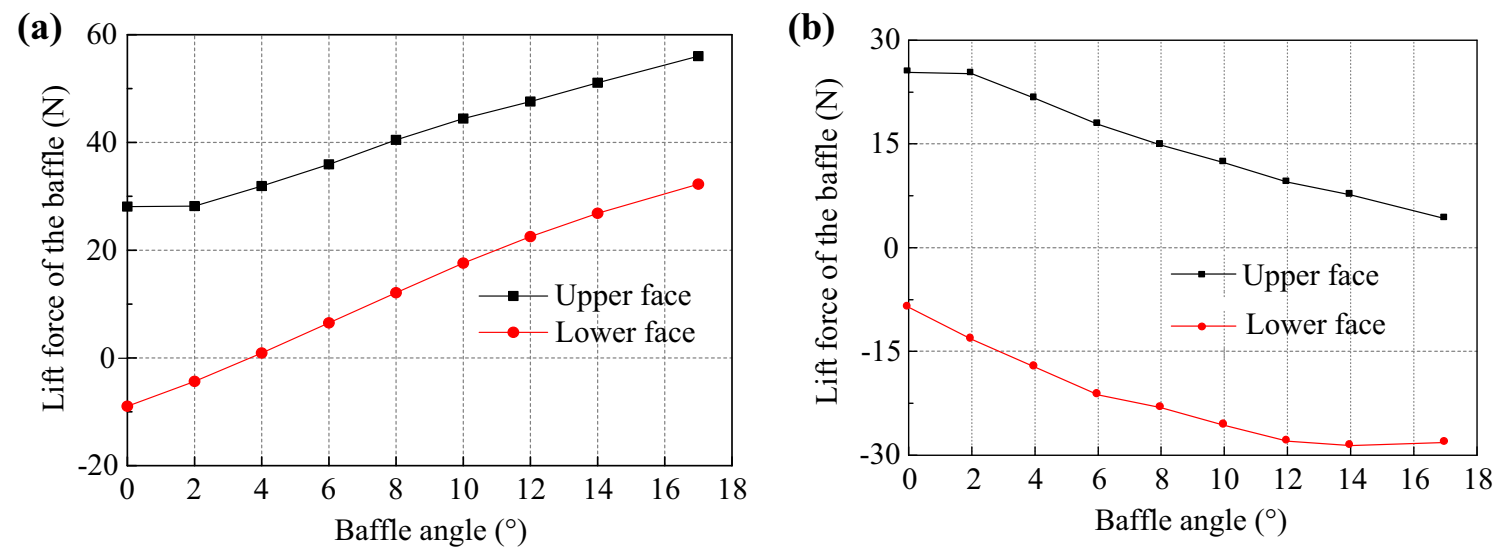

Fig. 9 Lift force of the upper and lower surfaces of the baffle: a knuckle-downstream condition; b knuckle-upstream condition

(a)

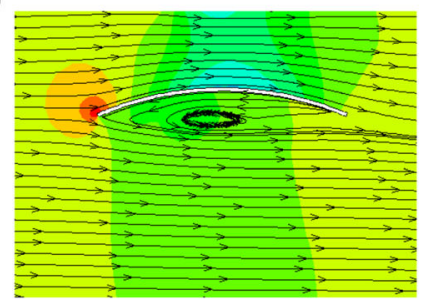

(d)

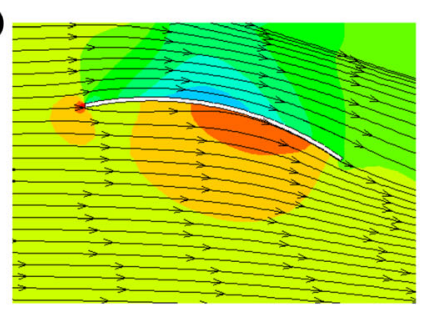

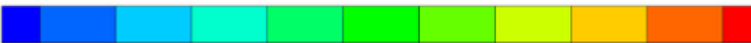

$-6000-5000-4000-3000-2000-1000 \quad 0 \quad 1000 \quad 2000 \quad 3000 \quad P a$

(b)

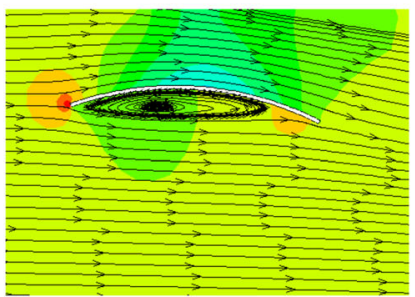

(e)

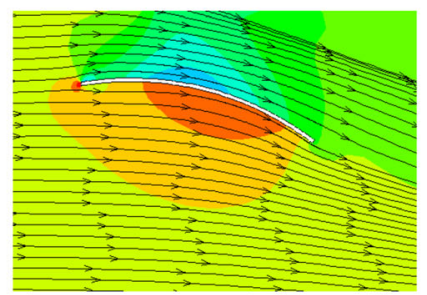

(c)

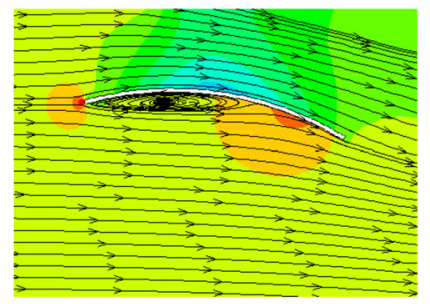

(f)

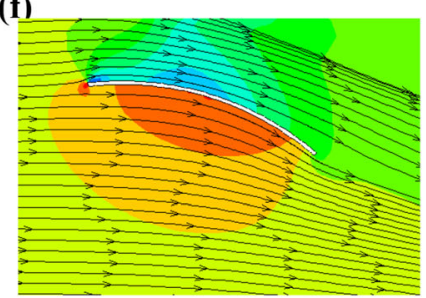

Fig. 10 Pressure and streamlines around the baffle in the knuckle-downstream operating condition: a $0^{\circ} ; \mathbf{b} 4^{\circ} ;$ c $8^{\circ} ; \mathbf{d ~} 12^{\circ} ;$ e $14^{\circ} ; \mathbf{f} 17^{\circ}$

\subsection{Optimization on the aerodynamic uplift force}

Based on the above research results, the angle interval is reduced to $4^{\circ}-8^{\circ}$. In this section, pantograph models equipped with $4^{\circ}, 5^{\circ}, 6^{\circ}, 7^{\circ}$ and $8^{\circ}$ baffles are established for numerical simulation, and the lift forces of baffles in the knuckle-downstream and knuckle-upstream conditions are obtained, as shown in Fig. 12a. Figure 12b shows the aerodynamic uplift forces of the pantograph obtained by the multibody simulation.

It can be seen from Fig. 12a that the lift force of the baffle increases linearly with the angle in the knuckledownstream condition, and the lift force of the baffle basically decreases linearly with the increment of the angle in the knuckle-upstream operation, whereas the decreasing trend slows down when the angle is larger. The variation of the aerodynamic uplift force of the pantograph shown in Fig. 12b is completely consistent with the lift force of the baffle shown in Fig. 12a. However, the aerodynamic uplift force of the pantograph is obtained by means of multibody simulation. The consistency of the results also indicates the accuracy of the computational fluid dynamics and multibody simulation in this study. The two curves in Fig. 12b intersect at about $4.75^{\circ}$, indicating that the aerodynamic uplift forces of the pantograph in the knuckle-downstream and knuckle-upstream operating conditions are equal at the angle, and the aerodynamic uplift force is $48 \mathrm{~N}$. Moreover, the static uplift force is $80 \mathrm{~N}$, and the pantograph-catenary contact force is $128 \mathrm{~N}$ correspondingly.

According to the conclusion, the pantograph equipped with a $4.75^{\circ}$ baffle is numerically simulated to obtain the aerodynamic forces and moments of each component of the 


\section{Pressure $-6000-5000-4000-3000-2000-1000 \quad 0 \quad 1000 \quad 2000 \quad 3000 \quad \mathrm{~Pa}$}

(a)

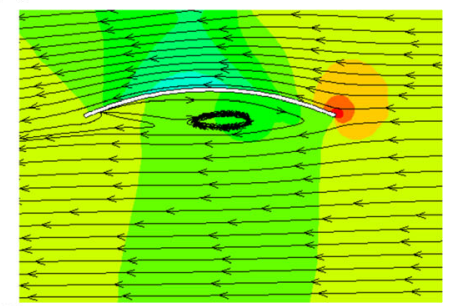

(d)

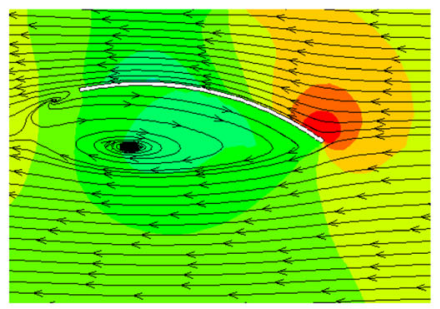

(b)

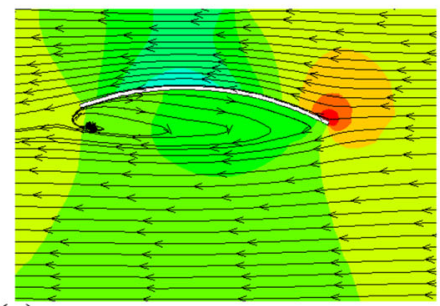

(e)

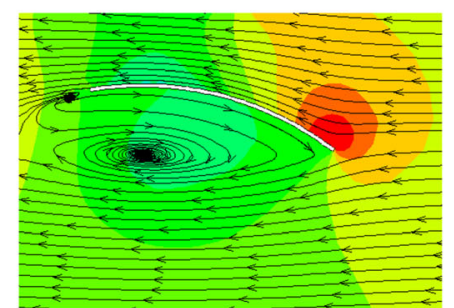

(c)

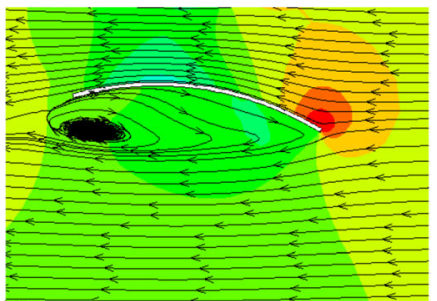

(f)

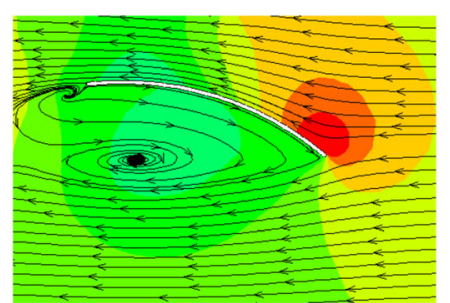

Fig. 11 Pressure and streamlines around the baffle in the knuckle-upstream operating condition: a $0^{\circ} ; \mathbf{b} 4^{\circ} ;$ c $8^{\circ} ; \mathbf{d ~} 12^{\circ} ;$ e $14^{\circ} ; \mathbf{f} 17^{\circ}$

Table 4 Aerodynamic forces of baffles and uplift force of the pantograph

\begin{tabular}{lllll}
\hline Condition & Baffle angle $\left(^{\circ}\right)$ & $\begin{array}{l}\text { Lift force of the } \\
\text { isolated baffle }(\mathrm{N})\end{array}$ & $\begin{array}{l}\text { Lift force of the baffle } \\
\text { installed at the pantograph }(\mathrm{N})\end{array}$ & $\begin{array}{l}\text { Aerodynamic } \\
\text { uplift force }(\mathrm{N})\end{array}$ \\
\hline Knuckle-downstream & 0 & 16.13 & 37.63 & 10.56 \\
& 17 & 79.15 & 160.77 & 132.50 \\
Knuckle-upstream & 0 & 17.91 & 36.16 & 81.47 \\
& 17 & -10.26 & -20.74 & 26.15 \\
\hline
\end{tabular}

(a)

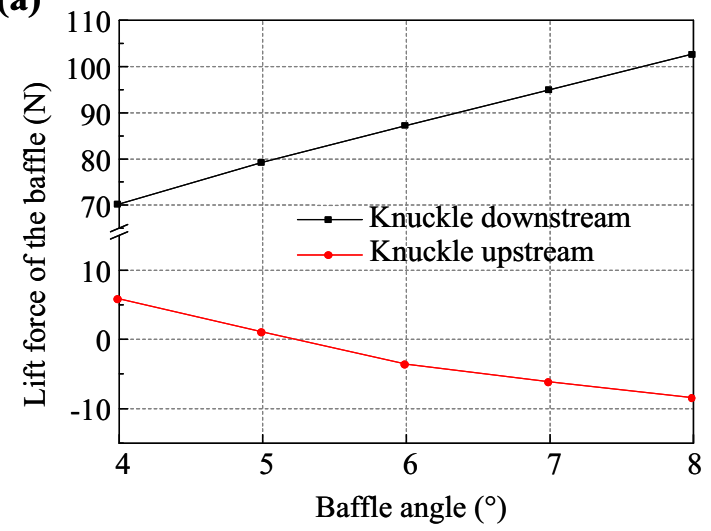

(b)

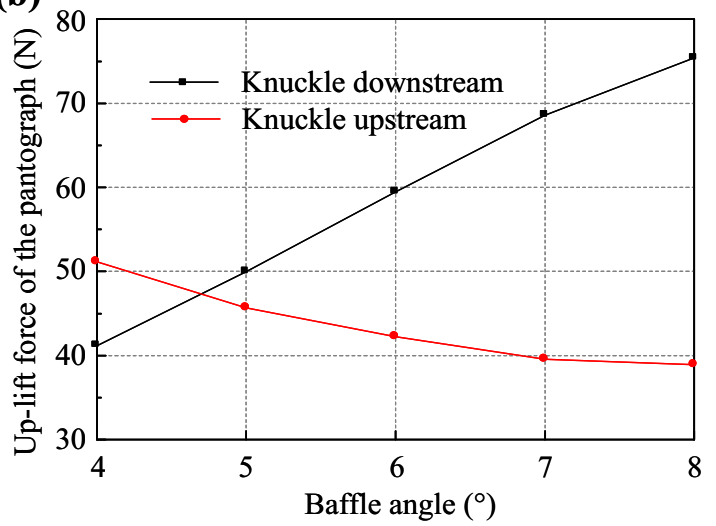

Fig. 12 Lift force and aerodynamic uplift force: a lift force of baffles with different angles; $\mathbf{b}$ uplift force of pantographs with different baffles

pantograph, and then the multibody simulation is performed to obtain the aerodynamic uplift force of the pantograph, as shown in Table 5.

The pantograph-catenary contact force is $128.89 \mathrm{~N}$ in the knuckle-downstream condition, and the contact force is $129.15 \mathrm{~N}$ in the knuckle-upstream condition. According to the requirements in the standard EN50367:2012, the pantograph-catenary contact force should be in the range of $110-180 \mathrm{~N}$ when the operating speed is $350 \mathrm{~km} / \mathrm{h}$. The optimization result satisfies the requirements of the standard. 
Table 5 Aerodynamic uplift forces of the original and optimized pantographs

\begin{tabular}{lllll}
\hline Condition & Baffle angle $\left(^{\circ}\right)$ & $\begin{array}{l}\text { Lift force of the baffle } \\
\text { and its support }(\mathrm{N})\end{array}$ & $\begin{array}{l}\text { Aerodynamic } \\
\text { uplift force }(\mathrm{N})\end{array}$ & $\begin{array}{l}\text { Pantograph-catenary } \\
\text { contact force }(\mathrm{N})\end{array}$ \\
\hline Knuckle downstream & No baffle & - & -27.10 & 52.9 \\
& 4.75 & 76.35 & 48.89 & 128.89 \\
Knuckle upstream & No baffle & - & 46.18 & 126.18 \\
& 4.75 & 1.89 & 49.15 & 129.15 \\
\hline
\end{tabular}

\section{Conclusions}

The aerodynamic performance of the pantograph is numerically simulated by computational fluid dynamics, and then the multibody simulation is performed to obtain the aerodynamic uplift force of the pantograph. According to the results, the pantograph baffles are optimized, and the following conclusions are obtained:

(1) The lift force of the baffle increases linearly with the angle in the knuckle-downstream condition. The lift force of the baffle basically decreases linearly with the increment of the angle in the knuckle-upstream operation, while the decreasing trend slows down when the angle is greater than $12^{\circ}$.

(2) It is determined that the optimal installation angle of the baffle is $4.75^{\circ}$. The pantograph-catenary contact forces in the knuckle-downstream and knuckle-upstream operating condition are $128.89 \mathrm{~N}$ and $129.15 \mathrm{~N}$, respectively. The values are nearly equal and both meet standard requirements.

(3) The optimization process of the aerodynamic uplift force of pantograph is proposed. It is universal and can be applied to various types of pantographs for the design and optimization of pantographs.

In addition to the above conclusions, this study still has some limitations. Although the optimization process of the aerodynamic uplift force of the pantograph is applicable to all speed levels, and the optimal model under the corresponding speed level can be obtained by this method, the work does not develop a specific relationship between the optimal model and speed. Therefore, the relationship between the optimal angle of the baffle and the operating speed need further study to improve the overall performance of pantographs.

Acknowledgements This project was supported by National Key Research and Development Program of China (No. 2020YFA0710902), National Natural Science Foundation of China (No. 52072319), National Natural Science Foundation of China (Nos. 52072319 and 12172308), and State Key Laboratory of Traction Power (2019TPL_T02).
Open Access This article is licensed under a Creative Commons Attribution 4.0 International License, which permits use, sharing, adaptation, distribution and reproduction in any medium or format, as long as you give appropriate credit to the original author(s) and the source, provide a link to the Creative Commons licence, and indicate if changes were made. The images or other third party material in this article are included in the article's Creative Commons licence, unless indicated otherwise in a credit line to the material. If material is not included in the article's Creative Commons licence and your intended use is not permitted by statutory regulation or exceeds the permitted use, you will need to obtain permission directly from the copyright holder. To view a copy of this licence, visit http://creativecommons. org/licenses/by/4.0/.

\section{References}

1. Pombo J, Ambrósio J, Pereira M et al (2009) Influence of the aerodynamic forces on the pantograph-catenary system for highspeed trains. Veh Syst Dyn 47(11):1327-1347

2. Song Y, Wang Z, Liu Z et al (2021) A spatial coupling model to study dynamic performance of pantograph-catenary with vehicletrack excitation. Mech Syst Signal Process 151:107336

3. Gao G, Hao J, Wei WF et al (2016) Dynamics of pantographcatenary arc during the pantograph lowering process. IEEE Trans Plasma Sci 44(99):2715-2723

4. Gao G, Yan X, Yang Z et al (2019) Pantograph-catenary arcing detection based on electromagnetic radiation. IEEE Trans Electromagn Compat 61(4):983-989

5. Collina A, Fcchinetti A, Fossati F, Resta F (2004) Hardware in the loop test-rig for identification and control application on high speed pantographs. Shock Vib 11(3):2171-2176

6. Zhang W, Mei G, Wu X, Shen Z (2002) Hybrid simulation of dynamics for the pantograph-catenary system. Veh Syst Dyn 38(6):393-414

7. Kim H, Hu Z, Thompson D (2020) Effect of cavity flow control on high-speed train pantograph and roof aerodynamic noise. Railw Eng Sci 28(1):54-74

8. Tian H (2019) Review of research on high-speed railway aerodynamics in China. Transport Saf Environ 1(1):1-21

9. Li X, Tan Y, Qiu X, Gong Z, Wang M (2021) Wind tunnel measurement of aerodynamic characteristics of trains passing each other on a simply supported box girder bridge. Railw Eng Sci 29(2):152-162

10. Xiang Z, Zhi J, Huang J et al (2019) A systematic approach for streamlined head form design and evaluation of Chinese highspeed train. Int J Rail Transport 7(2):117-139

11. Yao S, Guo D, Yang G, Gao L (2012) Distribution of high-speed train aerodynamic drag. J China Railw Soc 34(7):18-23 (in Chinese) 
12. Zhang J, Liu Z, Lu X (2015) Study on aerodynamics development of high-speed pantograph and catenary. J China Railw Soc 37(1):7-15 (in Chinese)

13. Song HL, Wu J, Wu Y, Zheng J, Zheng Q (2010) Influence of aerodynamic to high speed pantograph current collection characteristics. Electr Railw 21(1):28-32 (in Chinese)

14. Li L, Chen G (2018) Simulation of high-speed pantograph dynamic performance based on finite element model and aerodynamic pantograph model. J Phys: Conf Series 1064:012027

15. Yang Z (2009) Aerodynamics based study of pantograph highspeed current collection. Electr Railw 20(3):20-23 (in Chinese)

16. Li R, Zhou N, Zhang W, Mei G, Chen Z (2012) Calculation and analysis of pantograph aerodynamic uplift force. J China Railw Soc 34(8):26-32 (in Chinese)

17. Li T, Dai Z, Yu M, Zhang W (2021) Numerical investigation on the aerodynamic resistances of double unit trains with different gap lengths. Eng Appl Comp Fluid 15(1):549-560
18. Li T, Hemida H, Zhang J et al (2018) Comparisons of shear stress transport and detached eddy simulations of the flow around trains. J Fluids Eng 140(11):111108

19. Li T, Qin D, Zhang J (2019) Effect of RANS turbulence model on aerodynamic behavior of trains in crosswind. Chinese J Mech Eng 32(1):85

20. Zhang WH (2013) Dynamic of coupled system in high-speed trains: theory and practice. Science Press, Beijing

21. BS EN 14067-6:2010. Railway applications-Aerodynamics Part 6: Requirement and test procedures for cross wind assessment. Brussels: CEN, 2010.

22. BS EN 50367-2012+A1-2016. Railway applications: Current collection systems. Technical criteria for the interaction between pantograph and overhead line

23. Dai Z, Li T, Zhang W, Zhang J (2020) Numerical study on aerodynamic performance of high-speed pantograph with double strips. Fluid Dyn Mater Process 16(1):31-40 